\title{
Analisa Operabilitas serta Evaluasi Aspek Slamming dan Greenwater pada Tugboat - Studi Kasus Towing FSO Arco Ardjuna dari Jurong Port menuju Ardjuna Marine Terminal
}

\author{
Rainhart Gabriel, Eko B. Djatmiko, dan Mas Murtedjo \\ Jurusan Teknik Kelautan, Fakultas Teknologi Kelautan, Institut Teknologi Sepuluh Nopember (ITS) \\ Jl. Arief Rahman Hakim, Surabaya 60111 Indonesia \\ e-mail: ebdjatmiko@oe.its.ac.id
}

\begin{abstract}
Abstrak- AHTS (Anchor Handling Tug Supply) MP Premier adalah kapal penarik yang digunakan dalam operasi towing FSO Arco Ardjuna dari jurong port menuju ardjuna marine terminal. Penelitian ini menganalisa gerakan AHTS MP Premier saat operasi towing dalam ranah time domain, selain itu Penelitian ini meninjau kemungkinan terjadinya slamming dan greenwater dengan melakukan analisa respon spektra relatif vertikal haluan AHTS MP Premier berdasarkan RAO heave dan pitch. Aspekaspek tersebut dibandingkan dengan kriteria seakeeping untuk mengetahui kemampuan AHTS dalam melakukan operasi towing. Semua analisa dilakukan dalam keadaan melaju dengan kecepatan 5 knot untuk sejumlah arah propagasi gelombang. Didapat Gerakan rata-rata roll terbesar 4,53 deg pada kondisi $85 \%$ fuel tank dengan arah gelombang $120^{\circ}$, nilai rata-rata pitch terbesar 3,42 deg pada kondisi $85 \%$ fuel tank dengan arah datang gelombang $180^{\circ}$, nilai signifikan percepatan heave terbesar 1,98 $\mathrm{m} / \mathrm{s} 2$ pada kondisi $85 \%$ fuel tank dengan arah datang gelombang 180 dan nilai signifikan kecepatan heave terbesar $2,36 \mathrm{~m} / \mathrm{s}$ pada kondisi $85 \%$ fuel tank dengan arah datang gelombang $180^{\circ}$. sedangkan probability slamming terbesar 0,01259 pada kondisi $85 \%$ fuel tank dengan arah datang gelombang $180^{\circ}$ dan probability greenwater terbesar 0,01741 pada kondisi full load dengan heading $180^{\circ}$. Berdasarkan aspek tersebut didapat operabilitas AHTS MP Premier saat pross towing sebesar 98,99\% dengan batas gelombang general criteria sebesar $4 \mathrm{~m}$.
\end{abstract}

Kata Kunci-AHTS, greenwater, operability, slamming, towing

\section{PENDAHULUAN}

$\mathrm{F}$ SO Arco Ardjuna adalah wahana apung yang dimiliki oleh PT. Pertamina Hulu Energi Offshore Northwest Jave (PHE ONWJ) sebagai fasilitas penerima, penyimpanan, dan penyalur crude oil untuk mendukung proses produksi pada Ardjuna Marine Terminal. Sejarah perkembangan FSO tercatat bahwa FSO Arco Ardjuna merupakan salah satu FSO tertua yang beroperasi mulai tahun $1978^{[1]}$. Kondisi saat ini, FSO Arco Ardjuna sedang dilakukan reparasi dry docking di Jurong, Singapore. Setelah proses docking selesai, FSO Arco Ardjuna akan kembali dibawa menuju ardjuna marine terminal dengan proses towing. Proses towing dilakukan dikarenakan FSO Arco Ardjuna adalah struktur yang tidak memiliki sistem penggerak.

Proses towing FSO Arco Ardjuna dibantu menggunakan AHTS MP Premier. Rute pelayaran towing FSO Arco Ardjuna akan melewati dua perairan yaitu Laut Cina Selatan dan Laut
Jawa dengan jarak tempuh $808 \mathrm{~nm}$. Dengan kecepatan 5 knot, towing berlangsung selama $161 \mathrm{jam}$.

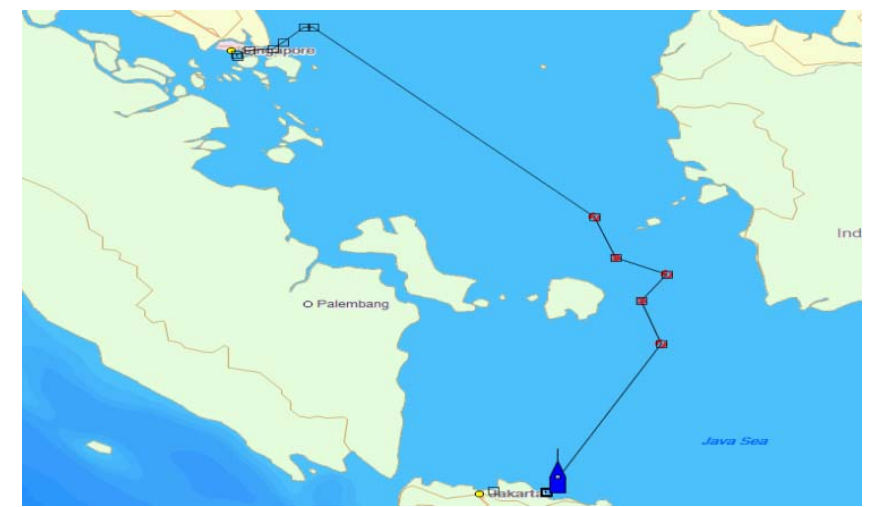

Gambar 1. Rute Pelayaran towing FSO Arco Ardjuna (Sumber PHE ONWJ, 2014)

Peluang keberhasilan towing teletak pada kemampuan AHTS MP Premier sebagai struktur yang membawa FSO Arco Ardjuna hingga tujuan. Selama proses towing berlangsung gerakan kapal akan dipengaruhi oleh keadaan ligkungan dan towing line. Selain itu, tekanan yang terjadi saat terhempasnya haluan atau yang disebut slamming dan masuknya gelombang laut ke bagian atas haluan atau yang disebut greenwater selama towing berlangsung mungkin akan terjadi dan menghambat operasi towing.

Analisa AHTS MP Premier pada penelitian ini didasarkan pada aspek-aspek gerakan, porbability slamming, dan probability greenwater. Aspek-aspek tersebut akan ditinjau dengan kriteria seakeeping yang dipilih untuk mengetahui batas kemampuan struktur untuk beroperasi. Batas-batas kemampuan tersebut akan digunakan pada nenelitian ini dalam menentukan operabilitas AHTS MP Premier, sehingga Penelitian ini memberikan informasi peluang keberhasilan AHTS MP Premier saat melakukan operasi towing FSO Arco Ardjuna dari Jurong Port menuju Ardjuna Marine Terminal.

\section{URAIAN PENELITIAN}

Metode yang digunakan dalam analisa respon gerakan dibantu dengan simulasi time domain sedangkan untuk analisa 
greenwater dan slamming menggunakan Spektra Respon. Adapun langkah-langkah sebagai berikut:

\section{A. Mengumpulkan data}

Penelitian dilakukan dengan menggunakan data FSO Arco Ardjuna milik PT. PHE ONWJ dan AHTS MP Premier milik PT. Marcopolo Shipyard. Untuk kondisi lingkungan pelayaran menggunakan Kondisi 10-Tahunan ${ }^{[2]}$ dimana Laut Cina Selatan memiliki Hs 4,6 m dengan Tp 8,4 s sedangkan Laut Jawa memiliki Hs 3,89 dengan Tp 7,97 s. Untuk Konfigurasi towing, AHTS berada tepat di depan FSO Arco Ardjuna.

Tabel 1. Pricipal Dimension FSO Arco Ardjuna ${ }^{[3]}$

\begin{tabular}{lcc}
\hline \multicolumn{1}{c}{ Designation } & Units & Maximum Operating Draft \\
\hline Length, LBP & $\mathrm{m}$ & 142,6 \\
Breadth, B & $\mathrm{m}$ & 48,2 \\
Depth, D & $\mathrm{m}$ & 26,5 \\
Draft to Baseline, T & $\mathrm{m}$ & 24 \\
Displacement & tonne & 153.202 \\
Waterplan Area & $\mathrm{m}^{2}$ & 6.239 \\
Cb & & 0,9 \\
LCB from zero pt. & $\mathrm{m}$ & $-2,78$ \\
LCF from zero pt. & $\mathrm{m}$ & $-2,79$ \\
KB & $\mathrm{m}$ & 12,02 \\
\hline \hline
\end{tabular}

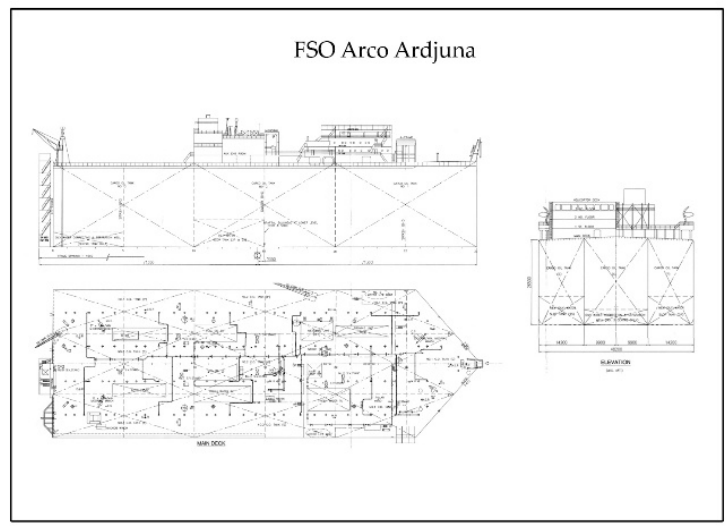

Gambar 2. General Arrangement FSO Arco Ardjuna

Tabel 2. Principal Dimension AHTS MP Premier ${ }^{[4]}$

\begin{tabular}{lcc}
\hline \multicolumn{1}{c}{ Designation } & Units & Maximum Operating Draft \\
\hline Length, LWL & $\mathrm{m}$ & 63,5 \\
Breadth, B & $\mathrm{m}$ & 16 \\
Depth, D & $\mathrm{m}$ & 6,5 \\
Draft to Baseline, & $\mathrm{m}$ & 5,5 \\
$\mathrm{~T}$ & & 3991,95 \\
Displacement & tonne & 907 \\
Waterplan Area & $\mathrm{m}^{2}$ & 0,698 \\
Cb & & 3,033 \\
KB & $\mathrm{m}$ & $-1,423$ \\
LCB from zero pt. & $\mathrm{m}$ & $-4,771$ \\
LCF from zero pt. & $\mathrm{m}$ & \\
\hline \hline
\end{tabular}

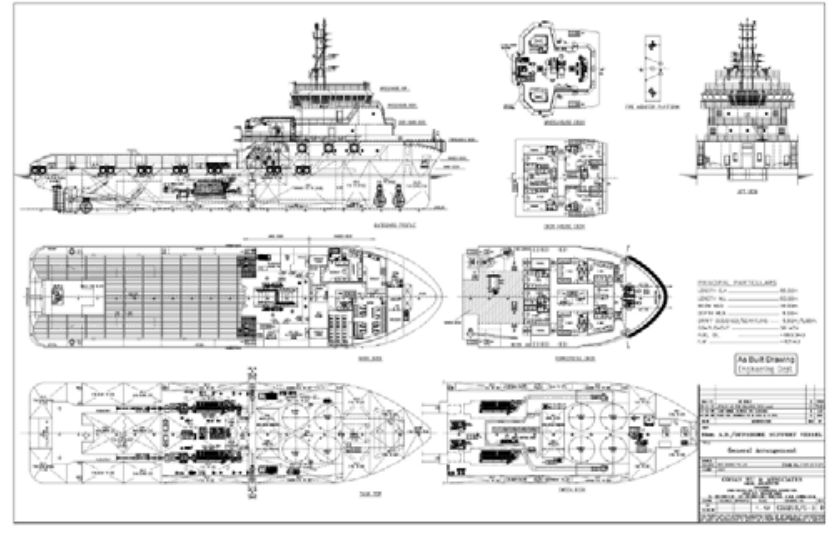

Gambar 3. General Arrangement AHTS MP Premier

\section{B. Pemodelan Struktur}

Pemodelan kedua struktur dibantu dengan perangkat lunak dan mengacu pada data ukuran utama kapal pada tabel 1 dan tabel 2. Pemodelan kedua struktur dibantu dengan perangkat lunak untuk mendapat linesplan.

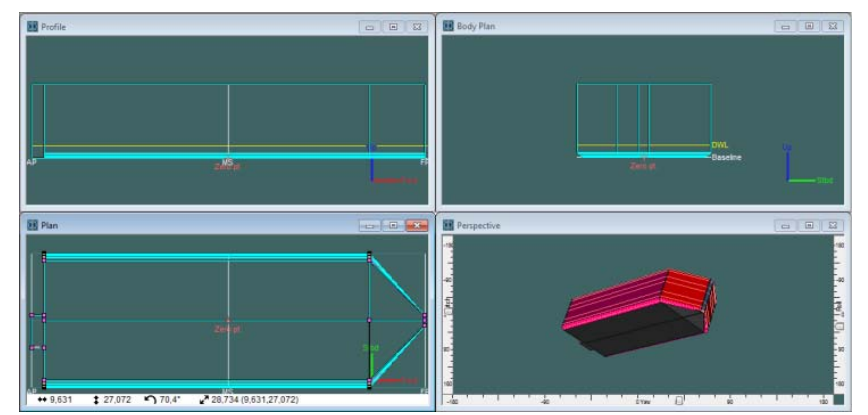

Gambar 4. Pemodelan FSO Arco Ardjuna

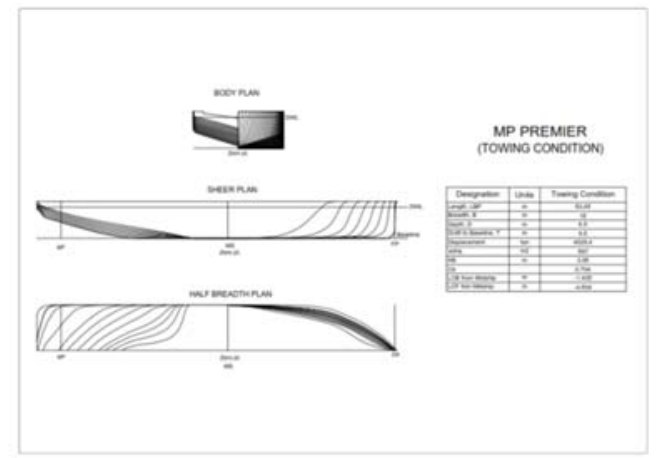

Gambar 5. Lines plan AHTS MP Premier

\section{Validasi Model}

Linesplan yang didapat dari pemodelan perlu divalidasi terlebih dulu untuk mengetahui apakah model yang dibuat sudah menyerupai data sebenarnya. Validasi dilakukan pada masing-masing model. Hasil koreksi pada validasi tidak boleh kurang dari $2 \%$. Pada analisa kedua model sudah sesuai dengan data sebenarnya sehingga dapat digunakan pada analisa selanjutnya. 
Tabel 3. Validasi FSO Arco kondisi towing load condition.

\begin{tabular}{lcccc}
\hline \hline \multicolumn{1}{c}{ Designation } & Units & Data & Model & Koreksi (\%) \\
\hline Length, LBP & $\mathrm{m}$ & 142,6 & 142,6 & 0,00 \\
Breadth, B & $\mathrm{m}$ & 48,2 & 48,2 & 0,00 \\
Draft to Baseline, T & $\mathrm{m}$ & 4,4 & 4,4 & 0,00 \\
Displacement & tonne & 27975 & 27602 & 1,33 \\
Waterplan Area & $\mathrm{m}^{2}$ & 6239 & 6255 & 0,26 \\
Cb & & 0,896 & 0,890 & 0,67 \\
LCB from zero pt. & $\mathrm{m}$ & $-2,69$ & $-2,74$ & 1,52 \\
LCF from zero pt. & $\mathrm{m}$ & $-2,801$ & $-2,808$ & 0,25 \\
KB & $\mathrm{m}$ & 2,243 & 2,235 & 0,36 \\
\hline \hline
\end{tabular}

Tabel 4. Validasi AHTS MP Premier full load condition

\begin{tabular}{lcccc}
\hline \hline \multicolumn{1}{c}{ Designation } & Units & Data & model & Koreksi (\%) \\
\hline Length, LWL & $\mathrm{m}$ & 63,5 & 63,45 & 0,08 \\
Breadth, B & $\mathrm{m}$ & 16 & 16 & 0,00 \\
Depth, D & $\mathrm{m}$ & 6,5 & 6,5 & 0,00 \\
Draft to Baseline & $\mathrm{m}$ & 5,5 & 5,5 & 0,00 \\
Displacement & tonne & 3991 & 4029 & 0,94 \\
Waterplan Area & $\mathrm{m}^{2}$ & 907 & 897 & 1,08 \\
Cb & & 0,69 & 0,704 & 0,86 \\
KB & $\mathrm{m}$ & 3,03 & 3,06 & 0,89 \\
LCB from zero pt. & $\mathrm{m}$ & $-1,42$ & $-1,43$ & 0,84 \\
LCF from zero pt. & $\mathrm{m}$ & $-4,77$ & $-4,83$ & 1,32 \\
\hline \hline
\end{tabular}

\section{Analisa Gerakan Relatif Vertikal Haluan}

Gerakan yang ditinjau pada analisa gerakan AHTS MP Premier saat towing memiliki titik acuan yang berbeda pada analisa greenwater dan slamming. Oleh karena itu, dilakukan analisa gerakan relatif vertikal haluan untuk bisa menganalisa kemungkinan terjadinya slamming dan greenwater. Gerakan relatif vertikal haluan dapat dinyatakan sebagai berikut :

$\left(Z_{\mathrm{br}}\right)_{a}=\sqrt{\left(Z_{b}\right)_{a}^{2}+\zeta_{a}^{2}+2\left(Z_{b}\right)_{a} \xi \theta_{a}} \cos \left(k_{e}-\varepsilon_{b}\right)$

Dimana:

(Zbr)a = Amplitudo gerak haluan relatif

$(\mathrm{Zb}) \mathrm{a}=$ Amplitudo gerak titik B

$\zeta \mathrm{a} \quad=$ Amplitudo gelombang

$\mathrm{k}_{\mathrm{e}} \quad=$ Angka gelombang efektif

$\varepsilon_{0} \quad=$ Sudut fase gerakan haluan vertikal

\section{E. Analisa Respon Gerakan}

Respon gerakan pada analisa gerakan saat towing dianalisa dalam ranah time domain selama $10800 \mathrm{~s}$ sesuai dengan ketentuan yang diberikan DNV OS E301 ${ }^{[5]}$ sedangkan pada probability slamming dan greenwater menggunakan spektrum respon. Walaupun begitu prinsip yang digunakan dalam melakukan analisa gerakan pada gelombang acak tetap sama yaitu perkalian antara RAO kuadrat baik reguler maupun relatif dengan spektrum gelombang, seperti pada persamaan (2)

$S R(\omega)=[R A O(\omega)]^{2} S(\omega)$
Dimana:

$\operatorname{Sr}(\omega)=$ Spektrum respon

$\mathrm{RAO}=$ Response Amplitude Operator

$\mathrm{S}(\omega)=$ Spektrum Gelombang

Jika Spektra Respons telah didapat maka nilai-nilai statistik gerakan dapat dihitung dengan formulasi matematis. Dalam ranah time domain pengolahan nilai $\mathrm{m}_{0}$ sebagai berikut:

$m_{0}=\frac{\sum_{n-1}^{N}\left(\zeta_{n}-\zeta\right)^{2}}{N}$

Dimana:

$\zeta \mathrm{n}=$ elevasi ke-n

$\mathrm{N}$ = jumlah sampel

Sedangkan pengolahan nilai $\mathrm{m}_{0}, \mathrm{~m}_{2}$, dan $\mathrm{m}_{4}$, dengan analisa spektrum respon menggunakan persamaan sebagai berikut ${ }^{[6]}$ :

$m_{0}=\int_{0}^{\infty} S j(\omega) d \omega$

$m_{2}=\int_{0}^{\infty} \omega^{2} S(\omega) d \omega$

$m_{4}=\int_{0}^{\infty} \omega^{4} S(\omega) d \omega$

$\mathrm{m}_{0}$ sebagai luasan di bawah kurva pada spektrum. Berdasarkan nilai tersebut dapat diolah dengan metode statistiik guna mendapat nilai rata-rata dan nilai signifikan amplitudo dengan persamaan:

$\begin{array}{ll}\mathrm{Hs} & =2\left(\mathrm{~m}_{\mathrm{o}}\right)^{0,5} \\ \mathrm{H}_{\mathrm{ave}} & =1,25\left(\mathrm{~m}_{\mathrm{o}}\right)^{0,5}\end{array}$

\section{F. Perhitungan Probability Slamming}

Persamaan peluang terjadinya slamming menggunakan respon gerak relatif vertikal haluan pada persamaan (9):

$p\left\{\check{z}_{R} \geq f^{1}(1)\right\}=e^{-\left(f^{1}(1)^{2}\right) / 2 m_{0}}$

\section{G. Perhitungan Probability Greenwater}

Persamaan peluang terjadinya greenwater juga menggunakan respon gerak relatif vertikal haluan dengan persamaa $(10)^{[7]}$ sebagai berikut:

$\operatorname{Pr}($ slam $)=\operatorname{Pr}\left(Z_{b r}>T_{b} d a n V_{b r}>V_{t h}\right)=\exp \left(-\frac{T_{b}^{2}}{2 m_{0 Z b r}}-\frac{V_{t h}^{2}}{2 m_{0 V b r}}\right)$

\section{H. Operabilitas}

Operabilitas dapat diartikan sebagai gambaran dari kemampuan struktur dalam beroperasi dengan membandingkan peluang struktur bekerja dengan data gelombang daerah operasi. Kemampuan struktur beroperasi ditentukan berdasarkan aspek-aspek menurut para ahli yang dirasa cukup mewakili dalam menjaga suatu struktur agar beroperasi baik.operablitas menggunakan persamaan (11):

Operabilitas $=\frac{T O H-W O W}{T O H} X 100 \%$

Dimana:

$\mathrm{TOH}=$ Time on hire

WOW $=$ Waiting on weathe 


\section{HASIL DAN DISKUSI}

\section{A. Analisa Respon Gerakan di Gelombang Reguler}

Analisa gerakan yang ditinjau dalam keadaan free floating pada gelombang reguler memiliki kecepatan 5 knot dengan arah datang gelombang $180^{\circ}, 150^{\circ}$, dan $120^{\circ}$. FSO Arco Ardjuna memiliki satu loading condition yaitu towing load dngan sarat 4,4 $\mathrm{m}$ dan AHTS MP Premier memiliki tiga loading condition yaitu full load dengan sarat 5,5, 85\% fuel tank dengan sarat 5,41 m dan $69 \%$ fuel tank dengan sarat 5,3 m. Hasil maksimum pada tiap gerakan dan kondisi masingmasing terdapat pada tabel 5 hingga tabel 8 .

Tabel 5. RAO FSO Arco Ardjuna towing load condition

\begin{tabular}{|c|c|c|c|c|c|}
\hline \multirow[b]{2}{*}{$\begin{array}{c}\text { Moda } \\
\text { Gerakan }\end{array}$} & \multicolumn{5}{|c|}{ RAO Maksimum } \\
\hline & Unit & 120 deg & 150 deg & $180 \mathrm{deg}$ & Max \\
\hline Heave & $\mathrm{m} / \mathrm{m}$ & 0,970 & 0,938 & 0,896 & 0,970 \\
\hline Roll & $\mathrm{deg} / \mathrm{m}$ & 5,786 & 3,340 & 0,000 & 5,786 \\
\hline Pitch & $\mathrm{deg} / \mathrm{m}$ & 0,576 & 0,829 & 0,965 & 0,965 \\
\hline
\end{tabular}

Tabel 6. RAO AHTS MP Premier full load condition

\begin{tabular}{cccccc}
\hline \hline $\begin{array}{c}\text { Moda } \\
\text { Gerakan }\end{array}$ & Unit & \multicolumn{5}{c}{ RAO Maksimum } & \multirow{2}{*}{ Max } \\
\hline Heave & $\mathrm{m} / \mathrm{m}$ & 0,997 & 1,063 & 1,402 & 1,402 \\
Roll & $\mathrm{deg} / \mathrm{m}$ & 7,311 & 5,055 & 0,023 & 7,311 \\
Pitch & $\mathrm{deg} / \mathrm{m}$ & 2,516 & 2,923 & 3,110 & 3,110 \\
\hline \hline
\end{tabular}

Tabel 7. RAO AHTS MP Premier 85\% fuel tank

\begin{tabular}{|c|c|c|c|c|c|}
\hline \multirow{2}{*}{$\begin{array}{c}\text { Moda } \\
\text { Gerakan }\end{array}$} & \multirow{2}{*}{ Unit } & \multicolumn{3}{|c|}{ RAO Maksimum } & \multirow{2}{*}{ Max } \\
\hline & & $120 \mathrm{deg}$ & $150 \mathrm{deg}$ & $180 \mathrm{deg}$ & \\
\hline Heave & $\mathrm{m} / \mathrm{m}$ & 0,997 & 1,073 & 1,420 & 1,420 \\
\hline Roll & $\mathrm{deg} / \mathrm{m}$ & 7,224 & 5,151 & 0,006 & 7,224 \\
\hline Pitch & $\mathrm{deg} / \mathrm{m}$ & 2,506 & 2,905 & 3,105 & 3,105 \\
\hline
\end{tabular}

Tabel 8. RAO AHTS MP Premier 69\% fuel tank

\begin{tabular}{|c|c|c|c|c|c|}
\hline \multirow{2}{*}{$\begin{array}{c}\text { Moda } \\
\text { Gerakan }\end{array}$} & \multirow{2}{*}{ Unit } & \multicolumn{3}{|c|}{ RAO Maksimum } & \multirow{2}{*}{ Max } \\
\hline & & $120 \mathrm{deg}$ & $150 \mathrm{deg}$ & 180 deg & \\
\hline Heave & $\mathrm{m} / \mathrm{m}$ & 0,999 & 1,083 & 1,435 & 1,435 \\
\hline Roll & $\mathrm{deg} / \mathrm{m}$ & 7,857 & 5,204 & 0,003 & 7,857 \\
\hline Pitch & $\mathrm{deg} / \mathrm{m}$ & 2,501 & 2,821 & 3,071 & 3,071 \\
\hline
\end{tabular}

\section{B. Konfigurasi Towing}

Analisa dilanjutkan dengan memodelkan operasi towing. Berdasarkan report yang dimiliki oleh PHE ONWJ ${ }^{[8]}$, Posisi AHTS MP Premier berada di depan FSO Arco Ardjuna terhubung dengan bantuan towing line dan tepat di belakang FSO Arco Ardjuna terdapat esccort tug untuk menjaga kecepatan dari operasi seperti pada gambar 6 .

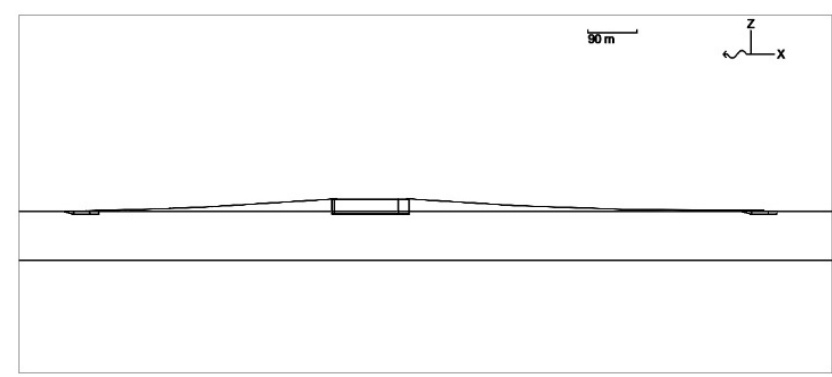

Gambar 6. Konfigurasi towing

\section{Analisa Gerak AHTS MP Premier pada Operasi Towing}

Berdasarkan konfigurasi yang dibuat, dilakukan analisa ranah time domain dengan bantuan software. Analisa gerakan yang diteliti adalah gerakan roll, pitch, heave displacement, heave velocity, dan heave acceleration. Analisa gerak ditampilkan dalam bentuk time domain seperti pada gambar 7. Dan diolah dengan persamaan 5 untuk mendapat nilai-nilai untuk dibandingkan dalam kriteria seakeeping.

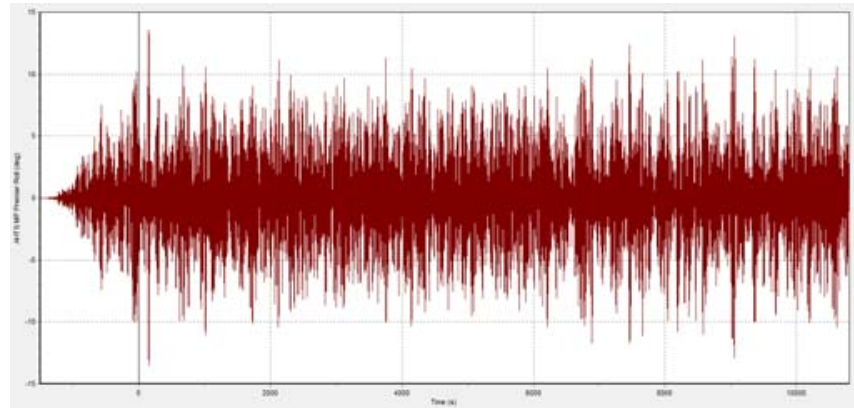

Gambar 7. Rekaman motion roll AHTS MP Premier 85\% fuel tank pada laut cina selatan kondisi operasi towing dengan heading $120^{\circ}$

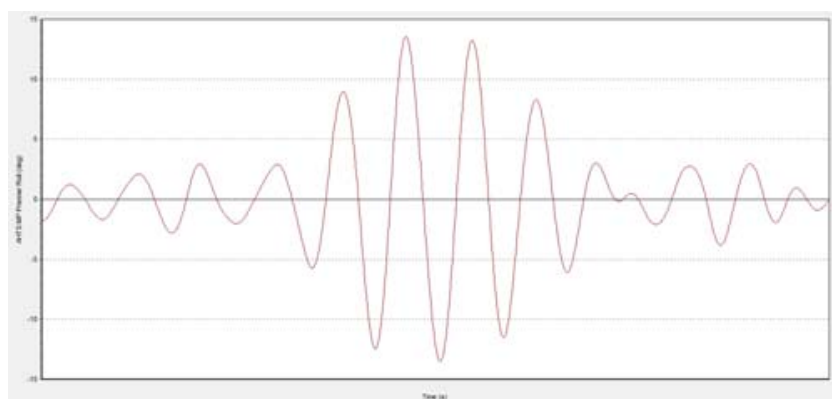

Gambar 8. Pembesaran rekaman motion roll AHTS MP Premier 85\% fuel tank pada laut cina selatan kondisi operasi towing dengan heading $120^{\circ}$

\section{Respon Gerak relatif haluan vertikal AHTS MP Premier pada Operasi Towing}

Respon gerak didapat dari hasil perkalian antara nilai RAO kuadrat dengan spektra gelombang. Pada analisa respon gerakan haluan vertikal didapatkan dengan menggunakan RAO gerak haluan vertikal berdasarkan RAO Couple Heave dan Pitch. Grafik respon gerak relatif halua vertikal terdapat pada gambar 8,9 , dan 10 .

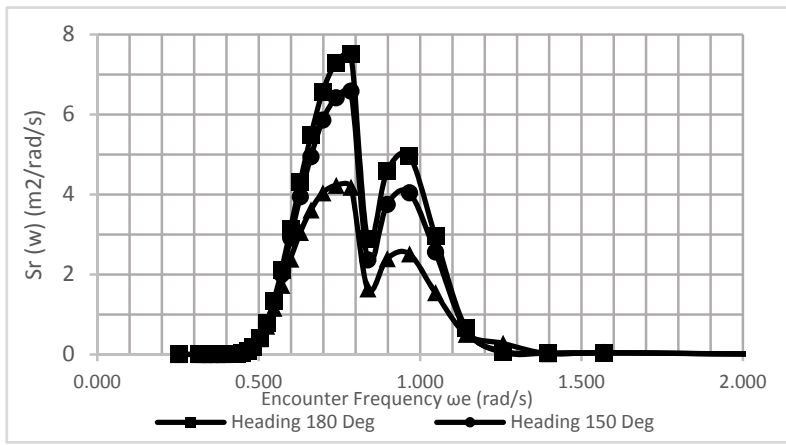

Gambar 9. Respon Spektra Gerak Relatif Vertikal Haluan AHTS MP Premier Full Load 


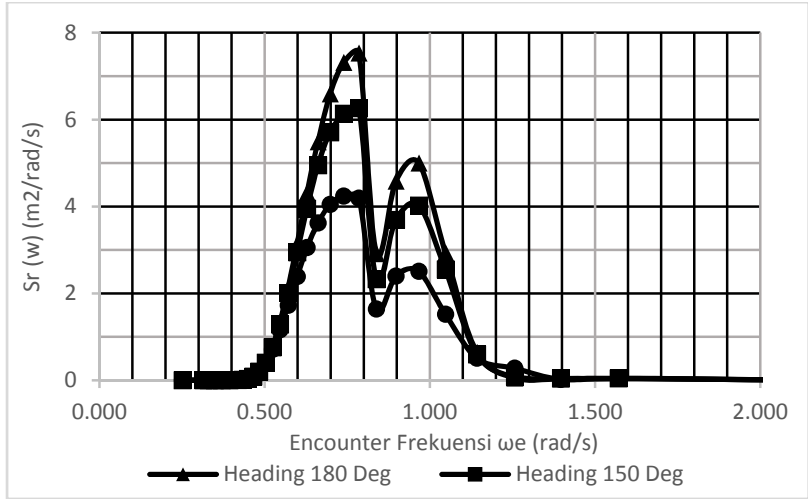

Gambar 10. Respon Spektra Gerak Relatif Vertikal Haluan AHTS MP Premier 85\% fuel tank

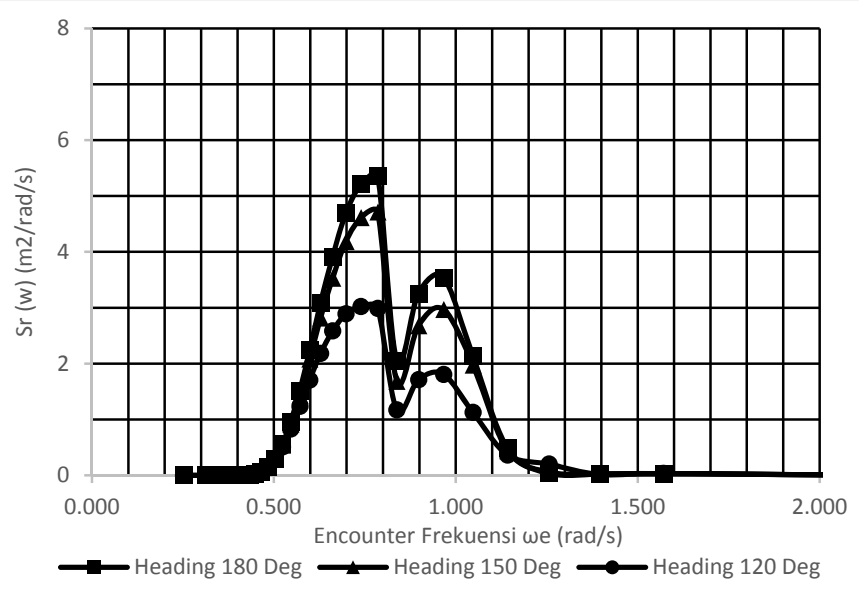

Gambar 11. Respon Spektra Gerak Relatif Vertikal Haluan AHTS MP Premier 69\% fuel tank

\section{E. Peluang Kejadian Slamming}

Berdasarkan harga spektra respon AHTS MP Premier pada tiap kondisi dan heading maka dapat dianalisa kemungkian terjadinya slamming menggunakan persamaan 9. Hasil analisa probability slamming dapat dilihat pada tabel 9.

Tabel 9. Probability slamming AHTS MP Premier

\begin{tabular}{ccc}
\hline \hline & Slamming AHTS MP Premier \\
& $\begin{array}{c}\text { Titik Tinjau FP } \\
\text { Kecepatan 5 Knot } \\
\text { Heading }\end{array}$ & Pr(slam) \\
\hline Kondisi & 180 & 0,011477 \\
Full Load - Hs 4,6 & 150 & 0,005448 \\
m & 120 & 0,000745 \\
& 180 & 0,012592 \\
85\% Load - Hs 4,6 & 150 & 0,007030 \\
m & 120 & 0,000945 \\
& 180 & 0,002608 \\
$69 \%$ Load - Hs & 150 & 0,001334 \\
$3,89 \mathrm{~m}$ & 120 & 0,000087 \\
\hline \hline
\end{tabular}

\section{F. Peluang Kejadian Greenwater}

Analisa peluang kejadian greenwater juga mengacu pada spektra respon AHTS MP Premier dengan menggunakan persamaan 10. Hasil peluang kejadian terdapat pada tabel 10.
Tabel 10. Probability greenwater AHTS MP Premier

\begin{tabular}{ccc}
\hline \hline & $\begin{array}{c}\text { Greenwater AHTS MP Premier } \\
\text { Titik Tinjau FP } \\
\text { Kecepatan 5 Knot } \\
\text { Heading }\end{array}$ & \\
Kondisi & 180 & Pf(greenwater) \\
\hline Full Load - Hs & 150 & 0,0174140 \\
$4,6 \mathrm{~m}$ & 120 & 0,0088637 \\
& 180 & 0,0014608 \\
85\% Load - Hs & 150 & 0,0143525 \\
4,6 m & 120 & 0,0081552 \\
& 180 & 0,0011654 \\
$69 \%$ Load - Hs & 150 & 0,0020709 \\
$3,9 \mathrm{~m}$ & 120 & 0,0009609 \\
& & 0,0000546 \\
\hline \hline
\end{tabular}

\section{G. Evaluasi Kriteria Seakeeping AHTS MP Premier saat} towing

Tiap nilai yang didapat dari hasil analisa gerakan, slamming, dan greenwater dibandingkan dengan kriteria seakeeping. Kriteria seakeeping dalam penelitian ini mengacu pada olson (1978) ${ }^{[9]}$ dan juga yamamoto (1984) ${ }^{[10]}$. Tabel 11 menunjukan kelayakan AHTS MP Premier terhadap kriteria seakeeping.

Tabel 11. Evaluasi kriteria seakeeping AHTS MP Premier

\begin{tabular}{|c|c|c|c|c|c|c|c|c|c|c|c|}
\hline Criteria & 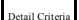 & Unit & & fall Load & & & & & & & \\
\hline & & & $180^{\circ}$ & $150^{\circ}$ & $120^{\circ}$ & $180^{\circ}$ & $150^{\circ}$ & $120^{\circ}$ & $180^{\circ}$ & $150^{\circ}$ & $120^{\circ}$ \\
\hline & 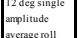 & deg & 0,002 & 2,625 & 4,466 & 0,003 & 2,64 & 4,526 & 0,002 & 1,474 & 2,488 \\
\hline & 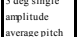 & deg & 3,415 & 3,142 & 2,55 & 3,421 & 3,261 & 2,552 & 2,89 & 2,819 & 2,275 \\
\hline eneral & 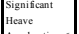 & & & & & & & & & & \\
\hline & 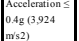 & $\mathrm{m}$ ms2 & 1,977 & 1,836 & 1,831 & 1,98 & 1,891 & 1,834 & 1,741 & 1,694 & 1,693 \\
\hline & Heare & & & & & & & 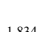 & 74 & & \\
\hline & 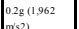 & mose & 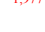 & 1,020 & $1,0,01$ & , & 1,091 & 1,034 & 1,141 & 1,094 & 1,093 \\
\hline & 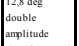 & deg & 0,006 & 8,4 & 14,29 & 0,008 & 8,448 & 14,482 & 0,006 & 4,718 & 7,97 \\
\hline 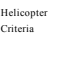 & 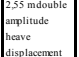 & $\mathrm{m}$ & 5,984 & 5,574 & 4,778 & 6,034 & 5,744 & 4,818 & 4,7512 & 4,676 & 4,024 \\
\hline & 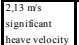 & mis & 2.361 & 221 & 2,064 & 2,362 & 2.278 & 2,068 & 1.979 & 1,954 & 1,836 \\
\hline mming and & 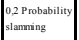 & & 0,01147 & 0.00544 & 0,00074 & 0,01259 & 0,00702 & 0.00094 & 0.0026 & 0,00133 & 0,00008 \\
\hline iteria & 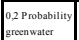 & . & 0,01741 & $0,0,08866$ & 0,00146 & 0,01435 & 0,00815 & 0,00116 & 0,00207 & 0,000966 & 0,00005 \\
\hline
\end{tabular}

\section{H. Evaluasi Kriteria Seakaaeping AHTS MP Premier}

Mengacu pada nilai gerakan dengan aspek seakeeping pada tabel 11. Setiap skenario yang memiliki nilai maksimum pada tiap aspek ditinjau kembali dengan melakukan varias tinggi gelombang signifikan untuk mengetahui batas-batas kemampuan AHTS yang tertera pada tabel 12 .

Tabel 12. Batas tinggi gelombang AHTS MP Premier dalam kriteria seakeeping

\begin{tabular}{|c|c|c|}
\hline Criteria & Detail Criteria & $\begin{array}{c}\mathrm{Hs} \\
\text { Maksimum }\end{array}$ \\
\hline \multirow{4}{*}{$\begin{array}{l}\text { General } \\
\text { Criteria }\end{array}$} & 12 deg single amplitude average roll & $>6 \mathrm{~m}$ \\
\hline & 3 deg single amplitude average pitch & $4 \mathrm{~m}$ \\
\hline & $\begin{array}{l}\text { Significant Heave Acceleration } \leq \\
0.4 \mathrm{~g}(3,924 \mathrm{~m} / \mathrm{s} 2)\end{array}$ & $>6 \mathrm{~m}$ \\
\hline & $\begin{array}{l}\text { Significant Heave Acceleration } \leq \\
0.2 \mathrm{~g}(1,962 \mathrm{~m} / \mathrm{s} 2)\end{array}$ & $4,5 \mathrm{~m}$ \\
\hline Helicopter & $\begin{array}{l}12,8 \text { deg double amplitude significant } \\
\text { roll }\end{array}$ & $4 \mathrm{~m}$ \\
\hline Criteria & $\begin{array}{l}2,55 \mathrm{~m} \text { double amplitude heave } \\
\text { displacement }\end{array}$ & $1,5 \mathrm{~m}$ \\
\hline
\end{tabular}


Tabel 13. Batas tinggi gelombang AHTS MP Premier dalam kriteria seakeeping (lanjutan)

\begin{tabular}{lll}
\hline \hline $\begin{array}{l}\text { Helicopter } \\
\text { Criteria }\end{array}$ & $2,13 \mathrm{~m} / \mathrm{s}$ significant heave velocity & $4 \mathrm{~m}$ \\
\hline $\begin{array}{l}\text { Slamming } \\
\text { and Deck }\end{array}$ & 0,2 Probability slamming & $4,5 \mathrm{~m}$ \\
$\begin{array}{l}\text { Wetness } \\
\text { Criteria }\end{array}$ & 0,2 Probability greenwater & $4,5 \mathrm{~m}$ \\
\hline \hline
\end{tabular}

\section{Operabilitas}

Dengan membandingkan nilai-nilai pada tabel 12 dan 13 dengan sebaran data gelombang, dapat diketahui berapa operabilitas AHTS MP Premier selama melakukan operasi towing FSO Arco Ardjuna dengan kecepatan 5 knot pada perairan laut cina selatan dan laut jawa. Sebaran data gelombang diwakili oleh sebaran data gelombag pada laut cina selatan . Operabilitas dapat dilihat pada tabel 14.

Tabel 14. Operabilitas AHTS MP Premier

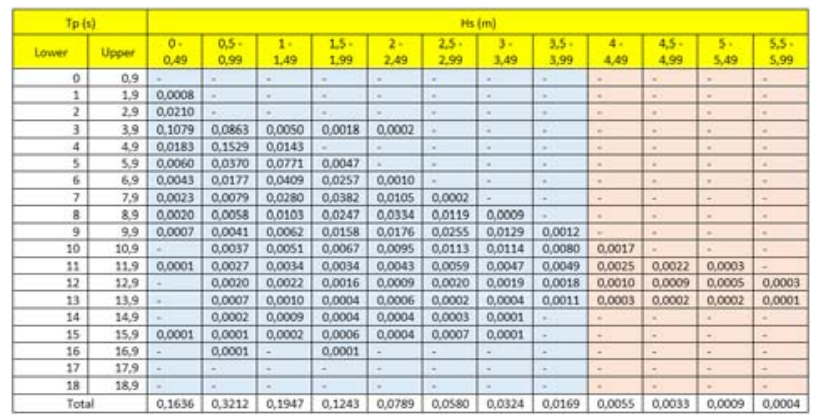

Berdasarkan persamaan 11, dapat diketahui nilai operabilitas AHTS MP Premier pada tabel 13. Nilai operabilitas yang ditinjau hanya berdasarkan general criteria dan slamming and greenwater criteria dikarenakan kedua kriteria tersebut akan selalu terjadi pada AHTS MP Premier selama operasi towing berlangsung. Sedangkan untuk helicopter criteria diangap tidak terjadi terus menerus selama operasi towing, akan tetapi analisa helicopter criteria tetap dilakukan untuk mengetahui batas gelombang jika operasi pemuatan terpaksa dilakukan saat operasi towing. Dengan batas kemampuan $\mathrm{Hs} 4 \mathrm{~m}$ untuk general criteria dan slamming and greenwater criteria didapat nilai operabilitas sebesar $98,99 \%$. Sedangkan jika operasi pemuatan terpaksa dilakukan AHTS MP Premier diijinkan melakukan operasi pada $\mathrm{Hs} 1,5 \mathrm{~m}$.

\section{KESIMPULAN/RINGKASAN}

Berdasarkan analisa data dan pembahasan, maka didapat kesimpulan sebagai berikut:

1. Gerakan AHTS MP Premier saat operasi towing FSO Arco Ardjuna memiliki nilai rata-rata roll terbesar 4,53 deg pada kondisi $85 \%$ fuel tank dengan arah gelombang $120^{\circ}$, nilai rata-rata pitch terbesar 3,42 deg pada kondisi $85 \%$ fuel tank dengan arah datang gelombang $180^{\circ}$, nilai signifikan percepatan heave terbesar $1,98 \mathrm{~m} / \mathrm{s} 2$ pada kondisi $85 \%$ fuel tank dengan arah datang gelombang $180^{\circ}$, nilai double signifikan roll terbesar 14,48 deg pada kondisi $85 \%$ fuel tank dengan arah datang gelombang $120^{\circ}$, nilai double heave terbesar $6,03 \mathrm{~m}$ pada kondisi $85 \%$ fuel tank dengan arah datang gelombang $180^{\circ}$, dan nilai signifikan kecepatan heave terbesar $2,36 \mathrm{~m} / \mathrm{s}$ pada kondisi $85 \%$ fuel tank dengan arah datang gelombang $180^{\circ}$.

2. Pada analisa probability slamming, didapat nilai probability kondisi full load dengan heading 180 deg sebesar 0,01147, full load dengan heading 150 deg sebesar 0,00544 , full load dengan heading 120 deg sebesar 0,00074, 85\% fuel tank dengan heading $180 \mathrm{deg}$ sebesar 0,01259, 85\% fuel tank dengan heading 150 deg sebesar 0,00702, 85\% fuel tank dengan heading 120 deg sebesar 0,00094, 69\% fuel tank dengan heading 180 deg sebesar 0,00260, 69\% fuel tank dengan heading $150 \mathrm{deg}$ sebesar 0,00133, dan 69\% fuel tank dengan heading $120 \mathrm{deg}$ sebesar 0,00008 .

3. Pada analisa probability slamming, didapat nilai probability greenwater pada kondisi full load dengan heading 180 deg sebesar 0,01741, full load dengan heading 150 deg sebesar 0,00886, full load dengan heading 120 deg sebesar 0,00146, 85\% fuel tank dengan heading 180 deg sebesar $0,01435,85 \%$ fuel tank dengan heading 150 deg sebesar 0,00815 , 85\% fuel tank dengan heading 120 deg sebesar 0,00116, 69\% fuel tank dengan heading 180 deg sebesar 0,00207, 69\% fuel tank dengan heading 150 deg sebesar 0,00096, dan 69\% fuel tank dengan heading 120 deg sebesar 0,00005 .

4. Operabilitas AHTS MP Premier saat operasi towing FSO Arco Ardjuna sebesar 98,99\% berdasarkan aspek general criteri, probability slamming dan greenwater dengan batas Hs $4 \mathrm{~m}$. Selain itu batas gelombang untuk AHTS MP Premier melakukan operasi pemindahan muatan/helicopter criteria adalah $\mathrm{Hs} 1,5 \mathrm{~m}$.

\section{UCAPAN TERIMA KASIH}

Penulis mengucapkan terima kasih kepada PT.Pertamina Hulu Energi Offshore Northwest Java (PT. PHE ONWJ) dan PT. Pelayaran Nasional Bina Buana Raya yang telah mendukung dalam hal data teknsik serta semua pihak yang terlah membantu penulis dalam mengerjakan penelitian ini.

\section{DAFTAR PUSTAKA}

[1] Ximenes, M. C., Design and Construction of a Floating Storage and Offloading Vessel Escravos LPG FSO (1997)

[2] International Maritime Organization, Guidelines for Safe Ocean Towing. London (1987)

[3] PHE ONWJ, FSO Arco Ardjuna Dry Docking - Project Overview. Jakarta (2014)

[4] Wartsila, MP Premier 65m A.H./ Offshore Support Vessel - Lghtship Survey \& Intact Stability Report (Final), Singapore (2011)

[5] DNV OS E301. Position Mooring. Norway (2004).

[6] Djatmiko, E.B., Perilaku dan Operabilitas Bangunan Laut di Atas Gelombang Acak, ITS Press, Surabaya (2012).

[7] Bhattacharyya. R., Dynamic of Marine Vehicles, New York: John Wiley \& Sons Inc (1972)

[8] PHE ONWJ, Towing Plan of FSO Arco Ardjuna. Jakarta (2015)

[9] Olson, S.R., An Evaluation of the Seakeeping Qualities of Naval Combatants, Naval Engineering Journal, ASNE, Vol. 90, No.1, pp. 2340 (1978).

[10] Llyod, A.R.J.M, Seakeeping: Ship Behavior in Rough Weather. Ellis Horwood Series in Marine Technology (1989) 